\title{
Effects of being uninsured or underinsured and living in extremely poor neighborhoods on colon cancer care and survival in California: historical cohort analysis, 1996-2011
}

Kevin M Gorey ${ }^{1 *}$, Isaac N Luginaah², Eric J Holowaty ${ }^{3}$, Guangyong Zou ${ }^{4}$, Caroline Hamm ${ }^{5}$ Emma Bartfay ${ }^{6}$, Sindu M Kanjeekal ${ }^{7}$, Madhan K Balagurusamy ${ }^{8}$, Sundus Haji-Jama ${ }^{9}$ and Frances C Wright ${ }^{10}$

\begin{abstract}
Background: We examined the mediating effects of health insurance on poverty-colon cancer care and survival relationships and the moderating effects of poverty on health insurance-colon cancer care and survival relationships among women and men in California.

Methods: We analyzed registry data for 3,291 women and 3,009 men diagnosed with colon cancer between 1996 and 2000 and followed until 2011 on lymph node investigation, stage at diagnosis, surgery, chemotherapy, wait times and survival. We obtained socioeconomic data for individual residences from the 2000 census to categorize the following neighborhoods: high poverty (30\% or more poor), middle poverty (5-29\% poor) and low poverty (less than 5\% poor). Primary health insurers were Medicaid, Medicare, private or none.

Results: Evidence of mediation was observed for women, but not for men. For women, the apparent effect of poverty disappeared in the presence of payer, and the effects of all forms of health insurance seemed strengthened. All were advantaged on 6-year survival compared to the uninsured: Medicaid $(R R=1.83)$, Medicare $(R R=1.92)$ and private $(R R=1.83)$. Evidence of moderation was also only observed for women. The effects of all forms of health insurance were stronger for women in low poverty neighborhoods: Medicaid $(R R=2.90)$, Medicare $(R R=2.91)$ and private $(R R=2.60)$. For men, only main effects of poverty and payers were observed, the advantaging effect of private insurance being largest. Across colon cancer care processes, Medicare seemed most instrumental for women, private payers for men.

Conclusions: Health insurance substantially mediates the quality of colon cancer care and poverty seems to make the effects of being uninsured or underinsured even worse, especially among women in the United States. These findings are consistent with the theory that more facilitative social and economic capital is available in more affluent neighborhoods, where women with colon cancer may be better able to absorb the indirect and direct, but uncovered, costs of care.
\end{abstract}

Keywords: Health insurance, Uninsured, Colon cancer care, Surgery, Chemotherapy, Wait times, Survival, Poverty, High poverty neighborhoods, Health care reform, California, United States

\footnotetext{
* Correspondence: gorey@uwindsor.ca

${ }^{1}$ School of Social Work, University of Windsor, 401 Sunset Avenue, Windsor, Ontario N9B 3P4, Canada

Full list of author information is available at the end of the article
} 


\section{Background}

A study of cancer survival in low-income areas of Toronto, Ontario, and Detroit, Michigan, during the 1980s found advantages among Canadians for common cancers including colon cancer [1]. The Canadian survival advantage was systematically replicated across diverse low-income Canadian and US contexts through the 1990s [2-8], culminating in a recent study of colon cancer treatment accessibility and survival in Toronto, Ontario, and San Francisco, California that followed its cohorts until 2006 [9]. In the United States, people with colon cancer who lived in low-income areas experienced less thorough lymph node evaluations and were less likely to receive indicated chemotherapies or to survive. More inclusive health insurance in Canada was advanced as the most plausible explanation.

All of these studies were ecological with respect to the measurement of socioeconomic status (SES). They typically used census tract data to define low-income neighborhoods where cancer patients lived, however, their lowest income areas only ranged from $10 \%$ to $20 \%$ poor. So they had limited power to study cancer care among "the truly disadvantaged" [10] who live, for example, in America's poorest neighborhoods where $30 \%$ to $40 \%$ or more of the households have incomes below the poverty line [10-12]. Recent synthetic and exploratory analyses have suggested the potential great policy importance of such study [13,14] and studies of colon cancer care may be particularly instructive in such contexts for several reasons.

First, colon cancer is the second most frequent cause of cancer death in America and its prognosis can be excellent with early diagnosis and treatment [15]. Second, generally modest inverse associations between income and colon cancer survival have been consistently observed in the US [1,9,16-19]. Third, as colon cancer screens have begun to be implemented and as effective chemotherapies proliferated during the 1990s for stage III colon cancer and more recently for stage II disease [20-22], evidence has mounted that the best care, from initial screening, through diagnostic investigations to follow-up care, is more accessible to people with higher SES [9,22-29]. Fourth, various underinsured statuses have also been associated with less than optimum colon cancer care in America [22,23,30-36]. Similar to international studies, these US studies have for the most part had insufficient power to study the quality of colon cancer care among those at greatest risk of not receiving it; the poor and the uninsured. Their samples of such people have tended to be quite small or nonexistent. One naturally wonders if even larger colon cancer survival disadvantages would be observed, for example, among more extremely poor people living in America's most impoverished places where health risks, including the risk of not having health insurance, are most prevalent.

\section{Combined effects of being underinsured and living in extremely poor communities}

Our previous within-US and Canada-US comparative studies of cancer care have allowed us to develop the theory that SES-cancer care relationships are probably mediated by health insurance $[9,13,37]$. We think that it is also probable that within the multi-payer US health care system the effects of various payers (self, Medicaid, Medicare and/or various private insurance companies) interact with other socioeconomic resources, personal and community, in complex ways that have not yet been studied. In fact, thus far this field has primarily advanced knowledge about main effects, that is, hypotheses about the independent effects of SES or various payers have been tested alone. More complex hypotheses about mediation and moderation effects have not been formally tested.

Our SES-payer-cancer care mediation theory borrows constructs from sociology, medicine and public health, and aims principally to model care gaps in America's most vulnerable communities. Its foundation is William Julius Wilson's germinal work in 1960s Chicago's high poverty neighborhoods (30\% or more poor) and Paul Jargowsky and Mary Jo Bane's construct validation of hundreds of extremely poor neighborhoods (40\% or more poor) across America between 1970 and 1990 [10-12]. Together they described places of prevalent demographic vulnerability that are particularly distressed for their lack of social and economic capital. In addition to the poor, all of the following groups of people tend to be more concentrated there: ethnic and racial minority group members, recent immigrants, young adults without a high school diploma, single mothers, the unemployed and those who have withdrawn from the labor market, part-time service workers versus full time skilled workers or professionals, renters versus home owners, welfare recipients and the homeless. Medicaid and Medicare, the government's, respective, mean-tested and entitlement, health care programs were specifically designed to mediate the effects of such concentrated impoverishment. But SES and various payers, including private ones, probably interact in other important ways across America's economic divide.

A recent survey practically demonstrated how SES and health insurance status could interact in the lives of real people with colon cancer. It surveyed nearly 300 people with stage III colon cancer, most of whom were insured and found that more than a third of them (38\%) suffered one or more significant financial hardships as a result of their treatment $[38,39]$. These included selling or refinancing their home, borrowing money from friends or 
family, experiencing an income decline of $20 \%$ or more, and prematurely withdrawing money from retirement accounts. Moreover, more than one of every ten of them reported coverage denials by their insurers and consequently one of every ten to fifteen of them was not able to adhere to their prescribed treatment regime. And perhaps not surprisingly, low-income households were much more likely to be so impacted. So it seems that the ultimate effectiveness of various health insurance programs may be significantly impacted or moderated by other available resources. And those most likely to be disadvantaged are the poor. It is they who will probably be least likely to pick up the indirect costs (time lost from work for numerous treatment visits, recuperation and perhaps travel) and direct, but uncovered costs (co-insurance and co-payments) of contemporary cancer care in America.

The objective of this study was to evaluate the mediating and moderating effects of SES and health insurance payer status on cancer care in extremely poor communities in the US. We hypothesized that the inverse poverty-colon cancer survival relationship would be mediated by payers (any payer would be better than being uninsured). We also hypothesized that the direct payer-colon cancer survival relationship would be moderated by poverty (all payers would be less effective in high poverty neighborhoods). Because gender is well known to be strongly associated with being poor and uninsured in the US [40,41] and our preliminary analyses suggested that survival disadvantages associated with poverty were greater for women than for men with colon cancer, we based our analyses upon the exploratory hypotheses that mediation and moderation effects would both be stronger among women. We then explored similar mediation and moderation hypotheses across the colon cancer care continuum: thoroughness of diagnostic investigation, stage of disease at diagnosis, receipt of and wait times for surgery and adjuvant chemotherapy, and receipt of palliative care.

\section{Methods}

The sampling frame was the California cancer registry which monitors the most populous US state. It ascertains nearly all colon cancer cases with a nearly perfect rate of microscopic confirmation [42,43]. Registry data was obtained for 6,300 colon cancer cases diagnosed between 1996 and 2000 (International Classification of Diseases, Ninth Revision code 153 [44]) and followed until 2011. Cases were randomly selected from 3 place and 3 poverty strata: megalopolises with between 3 and 12 million residents (greater San Diego, the San Francisco Bay area and greater Los Angeles), smaller metropolitan areas with populations between 400,000 and 900,000 (Salinas, Modesto, Stockton, Bakersfield and Fresno), and small rural places with populations of less than 10,000 and population densities less than 400 per $\mathrm{km}^{2}$ [45-47]. Overall, we sampled $15.4 \%$ of the colon cancer cases that were diagnosed in these places between 1996 and 2000. This study was powered to detect a difference of $5 \%$ in survival rates for women and men across 3 places and 3 poverty groups with $80 \%$ power at a 2 -tailed significance level of 5\% [48,49]. A 15\% oversample was drawn to account for unstaged cases and other missing data.

\section{Variables}

\section{Poverty and payers}

We first linked colon cancer patients to the US (2000) census by their residential census tract at diagnosis [45]. Next, to model our poverty measure after those that have been most validated, we defined the following neighborhoods: high poverty ( $30 \%$ or more poor), middle poverty $(5-29 \%)$ and low poverty (less than $5 \%$ poor) [10-14,50-52]. The prevalence of poverty in the typical high poverty neighborhood was 36\%, just about midpoint between Wilson's (30\%) and Jargowsky and Bane's (40\%) criterion definitions of high poverty. And the typically, quite low, annual household income in such high poverty neighborhoods of $\$ 23,150$ was much lower than that of typical households in middle $(\$ 42,475)$ or low poverty $(\$ 75,050)$ neighborhoods. Health insurance status, defined as the primary source of payment to the hospital or primary payer, was determined from medical records during the initial course of cancer directed treatment. It was categorized as follows: uninsured (self-pay or no source of payment), Medicaid, Medicare (with or without any supplementation or any other non-meanstest-based governmental payer: Veterans Affairs, TRICARE, the health care program for military service members, retirees and their families or the Indian Public Health Service) or private insurer (any managed care corporation or fee-for-service provider).

\section{Colon cancer care}

Variables were routinely extracted from hospital and physicians' office patient charts and clinic reports and coded by the California cancer registry [53-55]. These were stage of disease at diagnosis (according to the American Joint Committee on Cancer guidelines) [54], receipt of initial surgery, number of regional lymph nodes harvested for evaluation, receipt of adjuvant chemotherapy, wait times from diagnosis to surgery and chemotherapy, and survival time from diagnosis to death or last follow-up to 10 years. Defining characteristics of cancer stages were stage I (invasion into bowel wall muscle), stage II (invasion through bowel wall muscle), stage III (metastasized to at least 1 regional lymph node) and stage IV (distally metastasized). Stage 0 or in situ 
tumors were not sampled. Previous research has suggested a range of harvested lymph nodes, from 10 to 16 or more, as well as a range of surgical and post-surgical wait times for chemotherapy (1 month, 2 months or 3 months) that may be of clinical importance [56-62]. They were all examined.

\section{Statistical analyses}

We used logistic or binomial regression models to test hypotheses about the mediating and interaction effects of poverty and payer in predicting binary (survived or not) all-cause colon cancer survival [63-65]. Odds ratios (ORs) and 95\% confidence intervals (CIs) were estimated. Modest amounts of missing data would not enter regression models as discrete variables (yes or no) so they probably could not have confounded these analyses. We tested 2-way (gender-by-poverty and gender-by-payer) and 3-way interactions (genderby-poverty-by-payer) that involved gender. When any of these interactions were significant we assumed the pattern of findings to be different for women and men and reported them separately. Remarkably similar poverty-payer-survival patterns were observed across 2- to 10-year survival analyses. The 6-year analyses were reported as they were the best fit for women and men (Hosmer-Lemeshow test $[63,66]$ ).

Logistic regressions were used as statistical tests of complex models involving mediating and moderating effects and their ORs estimate the relative predictive weights of such interacting effects along with main effects. However, under the circumstances of this study, where both "exposures" (e.g., a third of the sample was selected from high poverty neighborhoods) and key outcomes (e.g., 6-year survival was $46 \%$ for the entire sample) are common, ORs probably overestimate rate ratios (RRs) [67]. So we provided accompanying practical assessments more germane perhaps to clinical and policy significance. All rates were directly adjusted for relevant covariates (age, stage, poverty and/or payers) using this study's sample as the standard. Then we used standardized RRs for all between-group comparisons with 95\% CIs derived from the Mantel-Haenszel $X^{2}$ test $[68,69]$. The statistical interaction is displayed at the bottom of Table 3, Corresponding practical significance indices (RRs) can be found in the Additional file. Finally, this study was reviewed and cleared by the University of Windsor's research ethics board.

\section{Results}

\section{Sample description}

The two key study variables of neighborhood poverty and primary payer are cross-tabulated in Table 1. People with colon cancer living in high poverty California neighborhoods were nearly twice as likely to be uninsured, five to nearly seven times as likely to be primarily insured by Medicaid, but only two-thirds to half as likely to be so covered by a private insurer as were their counterparts in low poverty neighborhoods. In a practical sense, all of the disadvantages seemed to be substantively greater for women. More detailed descriptive profiles of the California colon cancer patients in our sample are displayed in Table 2. A few characteristics stand out. This sample seems representative of California's diverse places, including high poverty neighborhoods where $30 \%$ or more of the households have aggregate annual incomes below the poverty live. As planned, a third of our sample lived there, while another third resided in so-called middle poverty neighborhoods that actually are still quite poor, with $5 \%$ to $29 \%$ of the household living below the poverty line. Demographically, our sample of generally older people with colon cancer seems consistent with expectations, nearly half of them covered by Medicare (44\%). The relatively low representation of the uninsured (8\%) may seem surprising. The vast majority of colon cancer care took place in hospitals where social work staff would work to connect patients who may have been uninsured at the time of their admission to any additional resources such as Medicaid or Medicare for which they qualified by virtue of being poor, older or disabled.

\section{Mediation (poverty-payer-survival) and moderation (poverty-by-payer) survival hypotheses}

Single predictor and full logistic regression models for 6year colon cancer survival among women and men are displayed in Table 3. Substantial support for both the mediation and moderation hypotheses was observed for women, but not for men. The top, left column, shows significant main effects of poverty and all payers (versus being uninsured) among women when these factors entered regression models alone. Moving down the column to the full model for women, consistent with mediation, the table shows that in the presence of payer the effect of poverty disappeared and effects of all of the payers were maintained or perhaps even strengthened. The 6-year survival rates among women whose primary payers were Medicaid $(R R=1.83)$, Medicare $(R R=1.92)$ or a private insurer $(R R=1.83)$ were all nearly twice that of uninsured women only $26 \%$ of whom so survived.

The hypothesis that the payer-colon cancer survival relationship would be moderated by poverty was also supported for women, but not for men. The statistical interaction is displayed at the bottom of Table 3, while the practical effect moderation is depicted at the bottom of the first table in the Additional file. Among women, all of the payers seemed less effective in high poverty neighborhoods than in low poverty neighborhoods and Medicaid did not seem any more effective than having 
Table 1 Primary payers among women and men with colon cancer diagnosed between 1996 and 2000 in low, middle and high poverty neighborhoods: prevalence estimates and prevalence ratios

\begin{tabular}{|c|c|c|c|c|c|c|c|c|}
\hline \multirow{2}{*}{$\frac{\text { Neighborhood poverty }}{\text { By primary payer }}$} & \multicolumn{4}{|c|}{ Women } & \multicolumn{4}{|c|}{ Men } \\
\hline & $\overline{N o} .^{a}$ & Prevalence & PR & $(95 \% \mathrm{Cl})$ & No. $^{a}$ & Prevalence & PR & $(95 \% \mathrm{Cl})$ \\
\hline \multicolumn{9}{|l|}{ Low Poverty } \\
\hline Uninsured & 60 & .056 & 1.00 & & 67 & .066 & 1.00 & \\
\hline Medicaid & 12 & .017 & 1.00 & & 16 & .014 & 1.00 & \\
\hline Medicare & 437 & .402 & 1.00 & & 358 & .381 & 1.00 & \\
\hline Private & 552 & .535 & 1.00 & & 598 & .542 & 1.00 & \\
\hline \multicolumn{9}{|l|}{ Middle Poverty } \\
\hline Uninsured & 74 & .069 & 1.23 & $(0.91,1.67)$ & 77 & .075 & 1.14 & $(0.83,1.56)$ \\
\hline Medicaid & 48 & .050 & 2.94 & $(1.79,4.83)$ & 26 & .026 & 1.86 & $(1.04,3.33)$ \\
\hline Medicare & 549 & .453 & 1.13 & $(1.02,1.25)$ & 408 & .436 & 1.14 & $(1.03,1.26)$ \\
\hline Private & 438 & .430 & 0.80 & $(0.73,0.87)$ & 480 & .467 & 0.86 & $(0.79,0.94)$ \\
\hline \multicolumn{9}{|l|}{ High Poverty } \\
\hline Uninsured & 105 & .098 & 1.75 & $(1.30,2.35)$ & 107 & .103 & 1.56 & $(1.17,2.07)$ \\
\hline Medicaid & 110 & .110 & 6.47 & $(4.29,9.75)$ & 72 & .068 & 4.86 & $(2.89,7.93)$ \\
\hline Medicare & 587 & .501 & 1.25 & $(1.14,1.37)$ & 451 & .486 & 1.28 & $(1.16,1.42)$ \\
\hline Private & 319 & .295 & 0.55 & $(0.50,0.61)$ & 349 & .347 & 0.64 & $(0.58,0.71)$ \\
\hline
\end{tabular}

Notes. PR = standardized prevalence ratio, $\mathrm{Cl}=$ confidence interval. Confidence intervals were derived from the Mantel-Haenszel $\mathrm{X}^{2}$ test. All adjustments were internal and direct, using this study's population of colon cancer cases as the standard. A prevalence ratio of 1.00 was the between-place baseline. Middle and high poverty neighborhood payer prevalence estimates were compared to payer prevalence estimates in low poverty places.

a Number of incident colon cancer cases.

${ }^{b}$ Prevalence estimates were age-adjusted across these categories: $25-59,60-69,70-79$ and 80 or older.

no insurance. Consistent with the theory that more facilitative social and economic capital is available in more affluent, low poverty neighborhoods, the 6-year survival rates there among women whose primary payers were Medicaid $(R R=2.90)$, Medicare $(R R=2.91)$ or a private insurer $(R R=2.60)$ were all nearly three times that of uninsured women who lived there. As for men, only significant main effects of poverty and payer were observed.

\section{Effects of being uninsured or underinsured and living in extremely poor neighborhoods on colon cancer investigations, diagnoses and treatments Investigation and stage at diagnosis}

Generally modest effects of poverty and payer that did not differ significantly by gender demonstrated the lymph node investigation criterion of 15 or more to be most predictive in this sample. A significant poverty by payer interaction was also found (left column of Table 4). In low poverty areas, colon cancer patients whose primary payer was Medicare were nearly twice as likely $(\mathrm{RR}=1.91)$ to have had 15 or more regional lymph nodes harvested during surgery for diagnostic evaluation than were the uninsured. Trends in the same direction that were not statistically significant, however, were observed for those primarily covered by Medicaid or private insurers. The combined any payer versus uninsured effect among those who lived in such more affluent neighborhoods approached significance ( $R R=1.64 ; 90 \%$ $\mathrm{CI}=1.06,2.53$, data not shown). No such effects of any payers were observed in high or middle poverty neighborhoods. There were only, relatively small, main effects of poverty and payer on early diagnosis of stage I or stage II disease.

\section{Surgery and adjuvant chemotherapy}

The effects of poverty and payer on the receipt of surgery for colon cancer patients with non-metastasized disease are displayed in Table 5. There were no apparent interaction effects. Full statistical models suggested disadvantaging effects of living in high poverty neighborhoods among women and middle poverty neighborhoods among men. They also strongly suggested the protective effects of Medicaid coverage for women $(\mathrm{OR}=10.14$ ) and private health insurance coverage for men $(\mathrm{OR}=$ 9.98). In a practical sense, any health insurance coverage (private, Medicare or Medicaid) increased surgical rates by $13 \%$ to $16 \%$ (RRs of 1.13 to 1.16 ). While practically all insured patients received such indicated care, only $86 \%$ of uninsured patients did. There were no significant main or interaction effects of poverty or primary payer on any surgical wait times.

The effects of poverty and payer on the receipt of adjuvant chemotherapy for colon cancer patients with stage II or stage III disease are displayed in Table 6. Three findings stand out. First, patients who lived in 
Table 2 Stratification, demographic, payer, investigation, staging and care characteristics of colon cancer patients diagnosed between 1996 and 2000 and followed until 2011

\begin{tabular}{|c|c|c|c|c|c|}
\hline & Sample & $\%$ & & Sample & $\%$ \\
\hline \multicolumn{6}{|c|}{ Stratification Characteristics } \\
\hline Places & \multicolumn{5}{|c|}{ Poverty prevalence (\%) in neighborhood } \\
\hline Large urban & 2,100 & 33.3 & $<5$ & 2,100 & 33.3 \\
\hline Smaller urban & 2,100 & 33.3 & $5-29$ & 2,100 & 33.3 \\
\hline Rural & 2,100 & 33.3 & $\geq 30$ & 2,100 & 33.3 \\
\hline \multicolumn{6}{|c|}{ Demographic Characteristics } \\
\hline Age at diagnosis, y & & & Gender & & \\
\hline $25-59$ & 1,347 & 21.4 & Female & 3,291 & 52.2 \\
\hline $60-69$ & 1,372 & 21.8 & Male & 3,009 & 47.8 \\
\hline $70-79$ & 1,919 & 30.5 & & & \\
\hline$\geq 80$ & 1,662 & 26.3 & & & \\
\hline Race/ethnicity & & & Primary Payers & & \\
\hline Non-Hispanic white & 4,199 & 66.7 & Medicare & 2,790 & 44.3 \\
\hline Non-Hispanic black & 688 & 10.9 & Private insurers & 2,736 & 43.4 \\
\hline Hispanic & 810 & 12.9 & Medicaid & 284 & 4.5 \\
\hline API or American Indian & 603 & 9.6 & Uninsured & 490 & 7.8 \\
\hline \multicolumn{6}{|c|}{ Investigation and Staging Characteristics } \\
\hline \multicolumn{3}{|c|}{ Number of regional lymph nodes examined } & \multicolumn{3}{|l|}{ Stage at diagnosis ${ }^{a}$} \\
\hline$<6$ & 2,199 & 37.5 & I & 1,300 & 22.5 \\
\hline $6-10$ & 1,513 & 25.8 & $\|$ & 1,882 & 32.6 \\
\hline $11-14$ & 874 & 14.9 & III & 1,392 & 24.1 \\
\hline$\geq 15$ & 1,278 & 21.8 & IV & 1,202 & 20.8 \\
\hline Missing data & 436 & 6.9 & Missing data & 524 & 8.3 \\
\hline \multicolumn{6}{|c|}{ Cancer Care Characteristics } \\
\hline Received surgery ${ }^{b}$ & 5,506 & 88.7 & Received chemotherapy & 1,751 & 28.3 \\
\hline Missing data & 90 & 1.4 & Missing data & 115 & 1.8 \\
\hline \multicolumn{2}{|c|}{ Wait time from diagnosis to surgery, $\mathrm{d}$} & \multicolumn{4}{|c|}{ Wait time after surgery for chemotherapy, $d$} \\
\hline$<14$ & 3,960 & 71.7 & $<14$ & 194 & 12.0 \\
\hline $14-29$ & 1,031 & 18.7 & $14-29$ & 415 & 25.7 \\
\hline $30-59$ & 408 & 7.4 & $30-59$ & 733 & 45.3 \\
\hline$\geq 60$ & 120 & 2.2 & $60-89$ & 159 & 9.8 \\
\hline \multirow[t]{2}{*}{ Missing data } & 781 & 12.4 & $\geq 90$ & 116 & 7.2 \\
\hline & & & Missing data & 134 & 7.6 \\
\hline
\end{tabular}

Note. API = Asian-Pacific Islander.

${ }^{a}$ American Joint Commission on Cancer staging [54].

b 5,227 were resections and 279 were local excisions.

high poverty neighborhoods were $18 \%$ less likely to have received post-surgical chemotherapy than were their counterparts in low poverty neighborhoods $(\mathrm{OR}=0.65$, $R R=0.82$ ). Second, the statistical models suggested that the poverty-chemotherapy wait time relationship might be mediated by payer as there seemed some attenuation of that poverty-therapy relationship in the presence of payer (unadjusted $\mathrm{OR}=1.55 ; 95 \% \mathrm{CI}=1.04,2.30$ and adjusted $\mathrm{OR}=1.33 ; 95 \% \mathrm{CI}=0.88,2.02$ ). In practical terms though, poverty and payer seemed independently important. The very poor were much more likely than the affluent to wait for 2 months or more after surgery to receive chemotherapy $(R R=1.38)$ and those with Medicare or private health insurance were half as likely as the uninsured or those with Medicaid to wait that long $(R R=0.52)$.

We developed a nominal measure of optimum treatment of stage III colon cancer from four study variables: received colon-cancer directed surgery within 30 days of diagnosis and received adjuvant chemotherapy within 45 days of surgery. Admittedly, it is probably only one of 
Table 3 Logistic regression results for main effects and interactions of neighborhood poverty and primary payer by gender on 6-year colon cancer survival

\begin{tabular}{|c|c|c|c|c|c|c|c|c|c|}
\hline \multirow[b]{2}{*}{ Predictor variables } & \multicolumn{5}{|c|}{ Women } & \multicolumn{4}{|c|}{ Men } \\
\hline & $\mathrm{No}^{\mathrm{a}}$ & & OR & & $(95 \% \mathrm{Cl})$ & $\mathrm{No}^{\mathrm{a}}$ & & OR & $(95 \% \mathrm{Cl})$ \\
\hline \multicolumn{10}{|c|}{ Single predictor models } \\
\hline \multicolumn{10}{|c|}{ Neighborhood poverty } \\
\hline$<5 \%$ poor & 1,061 & & 1.00 & & & 1,039 & & 1.00 & \\
\hline $5-29 \%$ poor & 1,109 & & 0.76 & & $(0.64,0.91)$ & 991 & & 0.68 & $(0.57,0.82)$ \\
\hline$\geq 30 \%$ poor & 1,121 & & 0.62 & & $(0.52,0.74)$ & 979 & & 0.57 & $(0.48,0.69)$ \\
\hline \multicolumn{10}{|l|}{ Primary payer } \\
\hline Uninsured & 239 & & 1.00 & & & 251 & & 1.00 & \\
\hline Medicaid & 170 & & 2.01 & & $(1.31,3.08)$ & 114 & & 1.24 & $(0.78,1.99)$ \\
\hline Medicare & 1,573 & & 2.48 & & $(1.79,3.43)$ & 1,217 & & 1.82 & $(1.34,2.48)$ \\
\hline Private & 1,309 & & 2.78 & & $(2.02,3.83)$ & 1,427 & & 2.36 & $(1.76,3.16)$ \\
\hline \multicolumn{10}{|c|}{ Full models } \\
\hline \multicolumn{10}{|l|}{ Neighborhood poverty } \\
\hline$<5 \%$ poor & 1,061 & & 1.00 & & & 1,039 & & 1.00 & \\
\hline $5-29 \%$ poor & 1,109 & & 1.07 & & $(0.78,1.48)$ & 991 & & 0.70 & $(0.58,0.84)$ \\
\hline$\geq 30 \%$ poor & 1,121 & & 1.25 & & $(0.71,2.18)$ & 979 & & 0.62 & $(0.52,0.75)$ \\
\hline \multicolumn{10}{|l|}{ Primary payer } \\
\hline Uninsured & 239 & & 1.00 & & & 251 & & 1.00 & \\
\hline Medicaid & 170 & & 2.40 & & $(1.55,3.73)$ & 114 & & 1.33 & $(0.83,2.12)$ \\
\hline Medicare & 1,573 & & 3.93 & & $(2.33,6.64)$ & 1,217 & & 1.79 & $(1.31,2.44)$ \\
\hline Private & 1,309 & & 3.66 & & $(2.36,5.67)$ & 1,427 & & 2.19 & $(1.63,2.93)$ \\
\hline Poverty by payer & 3,291 & & 0.87 & & $(0.78,0.98)$ & Null interac & remove & & \\
\hline \multicolumn{10}{|c|}{ Poverty by payer interaction among women } \\
\hline & \multicolumn{3}{|c|}{$>30 \%$ poor } & \multicolumn{3}{|c|}{$5-29 \%$ poor } & \multicolumn{3}{|c|}{$<5 \%$ poor } \\
\hline & No. ${ }^{a}$ & $\mathrm{OR}$ & $(95 \% \mathrm{Cl})$ & $\mathrm{No}^{\mathrm{a}}$ & OR & $(95 \% \mathrm{Cl})$ & $\mathrm{No}^{\mathrm{a}}$ & OR & $(95 \% \mathrm{Cl})$ \\
\hline \multicolumn{10}{|l|}{ Primary payer } \\
\hline Uninsured & 105 & 1.00 & & 74 & 1.00 & & 60 & 1.00 & \\
\hline Medicaid & 110 & 1.60 & $(0.90,2.84)$ & 48 & 1.83 & $(0.82,4.07)$ & 12 & 5.94 & $(1.50,23.54)$ \\
\hline Medicare & 587 & 1.68 & $(1.03,2.74)$ & 549 & 2.65 & $(1.48,4.75)$ & 437 & 4.69 & $(2.30,9.57)$ \\
\hline Private & 319 & 1.92 & $(1.18,3.13)$ & 438 & 2.61 & $(1.47,4.64)$ & 552 & 5.03 & $(2.51,10.08)$ \\
\hline
\end{tabular}

Notes. $\mathrm{OR}=$ odds ratio, $\mathrm{Cl}=$ confidence interval. All effects were age-adjusted across these categories: $25-59,60-69,70-79$ and 80 or older. After age, poverty and payer were accounted for, place (large urban, smaller urban, rural) did not enter the full models for women or men.

${ }^{a}$ Number of incident colon cancer cases.

a number of "optimum" care criterions with some measure of clinical validity. A statistical main effect of poverty was observed for women and a poverty-by-payer interaction effect was observed for men (Table 7). In low poverty neighborhoods about 7 of every 10 patients with stage III colon cancer received such optimum care and this outcome did not differ significantly between women and men. In high poverty neighborhoods, however, $20 \%$ fewer women received such optimum care $(R R=0.80)$. For men, there was no main effect of poverty, but there was an effect of payer in high poverty neighborhoods. Only 4 of every 10 such men in very poor neighborhoods who were either uninsured or insured by Medicaid received optimum care. Similarly poor men with Medicare or private health insurance were more than
$60 \%$ more likely to have received optimum care $(R R=$ 1.62). We also compared very poor uninsured men with very poor men who were insured by any payer, public or private. The vast majority of such uninsured men did not receive optimum care (29\%). However, very poor men with any type of health insurance were more than twice as likely to have received optimum care $(R R=2.30$; $95 \% \mathrm{CI}=1.10$, 1.43, data not shown). Rates for patient refusal of chemotherapy were similar (3\% overall) between poverty and payer groups.

\section{Experimental and palliative chemotherapies}

Chemotherapy for stage II colon cancer, experimental at the time of this study was not associated with gender or payer. But it was less likely to have been received by 
Table 4 Logistic regression results for main effects and interactions of neighborhood poverty and primary payer on high quality investigation and early stage at diagnosis

\begin{tabular}{|c|c|c|c|c|c|c|c|c|c|}
\hline \multirow[b]{2}{*}{ Predictor variables } & \multicolumn{5}{|c|}{15 or more regional lymph nodes examined } & \multicolumn{4}{|c|}{ Stage I or stage II at the time of diagnosis } \\
\hline & $\overline{\text { No. }^{a}}$ & & OR & & $(95 \% \mathrm{Cl})$ & No. $^{a}$ & & OR & $(95 \% \mathrm{Cl})$ \\
\hline \multicolumn{10}{|c|}{ Single predictor models } \\
\hline \multicolumn{10}{|l|}{ Neighborhood poverty } \\
\hline$<5 \%$ poor & 1,727 & & 1.00 & & & 1,959 & & 1.00 & \\
\hline $5-29 \%$ poor & 1,646 & & 0.92 & & $(0.79,1.07)$ & 1,923 & & 0.81 & $(0.72,0.92)$ \\
\hline$\geq 30 \%$ poor & 1,583 & & 0.95 & & $(0.81,1.11)$ & 1,894 & & $0.89^{*}$ & $(0.79,1.01)$ \\
\hline \multicolumn{10}{|l|}{ Primary payer } \\
\hline Uninsured & 241 & & 1.00 & & & 310 & & 1.00 & \\
\hline Medicaid & 229 & & 2.01 & & $(0.74,1.65)$ & 261 & & 1.06 & $(0.77,1.48)$ \\
\hline Medicare & 2,221 & & 1.11 & & $(0.81,1.53)$ & 2,601 & & 1.33 & $(1.04,1.71)$ \\
\hline Private & 2,265 & & 0.97 & & $(0.72,1.30)$ & 2,604 & & 1.30 & $(1.03,1.65)$ \\
\hline \multicolumn{10}{|c|}{ Full models } \\
\hline \multicolumn{10}{|c|}{ Neighborhood poverty } \\
\hline$<5 \%$ poor & 1,727 & & 1.00 & & & 1,959 & & 1.00 & \\
\hline $5-29 \%$ poor & 1,646 & & $1.34^{*}$ & & $(0.99,1.80)$ & 1,923 & & 0.82 & $(0.72,0.93)$ \\
\hline$\geq 30 \%$ poor & 1,583 & & 1.97 & & $(1.17,3.32)$ & 1,894 & & 0.91 & $(0.80,1.04)$ \\
\hline \multicolumn{10}{|l|}{ Primary payer } \\
\hline Uninsured & 241 & & 1.00 & & & 310 & & 1.00 & \\
\hline Medicaid & 229 & & 1.30 & & $(0.86,1.98)$ & 261 & & 1.07 & $(0.77,1.49)$ \\
\hline Medicare & 2,221 & & 2.03 & & $(1.22,3.41)$ & 2,601 & & 1.33 & $(1.03,1.70)$ \\
\hline Private & 2,265 & & $1.49^{*}$ & & $(0.97,2.29)$ & 2,604 & & 1.28 & $(1.01,1.63)$ \\
\hline Poverty by payer & 4,956 & & 0.85 & & $(0.76,0.94)$ & Null interacti & emoved & & \\
\hline \multicolumn{10}{|c|}{ Poverty by payer interaction on high quality investigation } \\
\hline & \multicolumn{3}{|c|}{$>30 \%$ poor } & \multicolumn{3}{|c|}{$5-29 \%$ poor } & \multicolumn{3}{|c|}{$<5 \%$ poor } \\
\hline & $\overline{\text { No. }^{a}}$ & OR & $(95 \% \mathrm{Cl})$ & $\mathrm{No}^{\mathrm{a}}$ & OR & $(95 \% \mathrm{Cl})$ & $\overline{\text { No. }^{a}}$ & OR & $(95 \% \mathrm{Cl})$ \\
\hline \multicolumn{10}{|l|}{ Primary payer } \\
\hline Uninsured & 114 & 1.00 & & 72 & 1.00 & & 55 & 1.00 & \\
\hline Medicaid & 144 & 1.11 & $(0.65,1.88)$ & 63 & 0.70 & $(0.32,1.53)$ & 22 & 1.91 & $(0.63,5.79)$ \\
\hline Medicare & 794 & 0.93 & $(0.58,1.48)$ & 753 & 0.92 & $(0.52,1.63)$ & 674 & 2.01 & $(1.02,3.99)$ \\
\hline Private & 531 & 1.00 & $(0.64,1.57)$ & 758 & 0.85 & $(0.50,1.45)$ & 976 & 1.32 & $(0.68,2.55)$ \\
\hline
\end{tabular}

Notes. $\mathrm{OR}=$ odds ratio, $\mathrm{Cl}=$ confidence interval. All effects were age-adjusted across these categories: $25-59,60-69,70-79$, and 80 or older.

${ }^{a}$ Number of incident colon cancer cases.

* $\mathrm{p}<.10$.

patients in mid- to high poverty (17\%) than in low poverty (25\%) neighborhoods $(\mathrm{R} R=0.68 ; 95 \% \mathrm{CI}=0.57$, 0.82 ). We also found a poverty-by-payer interaction such that in middle poverty neighborhoods the privately insured may have been slightly more likely to have received chemotherapy than were others, respectively, $24 \%$ and $18 \%(R R=1.29 ; 90 \% C I=1.00,1.66)$. Finally, we considered receipt of palliative chemotherapy by those with stage IV colon cancer. Straightforward independent main disadvantaging effects of mid- to high poverty (44\% versus $56 \%, \mathrm{RR}=0.80 ; 95 \% \mathrm{CI}=0.71,0.90$ ) and being uninsured or covered by Medicaid (38\% versus $51 \%, \mathrm{RR}=0.75 ; 95 \% \mathrm{CI}=0.62,0.91)$ that did not differ between women and men were observed.

\section{Discussion}

To the best of our knowledge, this is the first report of the combined effects of poverty and health insurance on colon cancer care in high poverty US neighborhoods. We found strong support for our hypothesis that health insurance mediates the poverty-colon cancer survival relationship for women. The apparent effect of poverty disappeared in the presence of payer and the effects of all forms of health insurance seemed strengthened. All were associated with substantial survival advantages compared to the uninsured: Medicaid $(R R=1.83)$, Medicare $(R R=1.92)$ and private $(R R=1.83)$. We also found support for our poverty-by-health insurance interaction hypothesis for women. The survival effects of all forms 
Table 5 Logistic regression results for main effects of neighborhood poverty and primary payer by gender on receipt of colon cancer surgery among patients with non-metastasized disease

\begin{tabular}{|c|c|c|c|c|c|c|}
\hline \multirow[b]{2}{*}{ Predictor variables } & \multicolumn{3}{|c|}{ Women } & \multicolumn{3}{|c|}{ Men } \\
\hline & $\mathrm{No}^{a}$ & OR & $(95 \% \mathrm{Cl})$ & $\mathrm{No}^{\mathrm{a}}$ & OR & $(95 \% \mathrm{Cl})$ \\
\hline \multicolumn{7}{|c|}{ Single predictor models } \\
\hline \multicolumn{7}{|c|}{ Neighborhood poverty } \\
\hline$<5 \%$ poor & 774 & 1.00 & & 713 & 1.00 & \\
\hline $5-29 \%$ poor & 762 & $0.50^{*}$ & $(0.24,1.06)$ & 675 & 0.32 & $(0.11,0.90)$ \\
\hline$\geq 30 \%$ poor & 761 & 0.38 & $(0.19,0.78)$ & 637 & $0.35^{*}$ & $(0.12,1.01)$ \\
\hline \multicolumn{7}{|l|}{ Primary payer } \\
\hline Uninsured & 94 & 1.00 & & 109 & 1.00 & \\
\hline Medicaid & 113 & 9.66 & $(1.12,83.68)$ & 74 & 2.49 & $(0.26,23.47)$ \\
\hline Medicare & 1,135 & 5.12 & $(1.85,14.20)$ & 844 & 3.80 & $(1.06,13.58)$ \\
\hline Private & 955 & 3.39 & $(1.30,8.88)$ & 998 & 10.09 & $(2.62,38.85)$ \\
\hline \multicolumn{7}{|c|}{ Full models } \\
\hline \multicolumn{7}{|l|}{ Neighborhood poverty } \\
\hline$<5 \%$ poor & 774 & 1.00 & & 713 & 1.00 & \\
\hline 5-29\% poor & 762 & $0.49^{*}$ & $(0.23,1.03)$ & 675 & 0.32 & $(0.11,0.91)$ \\
\hline$\geq 30 \%$ poor & 761 & 0.37 & $(0.18,0.77)$ & 637 & 0.41 & $(0.14,1.19)$ \\
\hline \multicolumn{7}{|l|}{ Primary payer } \\
\hline Uninsured & 94 & 1.00 & & 109 & 1.00 & \\
\hline Medicaid & 113 & 10.14 & $(1.17,87.92)$ & 74 & 2.82 & $(0.30,26.85)$ \\
\hline Medicare & 1,135 & 4.43 & $(1.58,12.47)$ & 844 & 3.93 & $(1.08,14.27)$ \\
\hline Private & 955 & $2.65^{*}$ & $(0.99,7.08)$ & 998 & 9.98 & $(2.53,39.33)$ \\
\hline
\end{tabular}

of health insurance were stronger in low poverty neighborhoods than they were in poor to very poor neighborhoods: Medicaid $(\mathrm{RR}=2.90)$, Medicare $(\mathrm{RR}=2.91)$ and private $(R R=2.60)$. It seems that the effectiveness of all health insurance programs is significantly impacted by the availability of other key resources. In more well to do neighborhoods where social and economic capital abounds most people with colon cancer seem quite able to absorb the indirect and additional uncovered, direct costs of cancer care. High poverty neighborhoods on the other hand, with their relative lack of such capital reserves, seem to remain as described more than a generation ago by William Julius Wilson, places of "true disadvantage" [10], places of multiplicative disadvantage, especially for the women who live there. Not only are they much more likely to be uninsured ( 2 times as likely as less poor women) or underinsured (more than 6 times as likely to be covered by Medicaid), but when insured, all such insurance programs, public and private, seem to be much less effective there than they are in less poor places. There is even some evidence to suggest that being covered by Medicaid may be no more beneficial than being uninsured among many women who live in such extremely poor places.
For men, poverty and health insurance still seem to matter very much, but in more straightforward ways, as independent main effects. Across colon cancer care processes, poverty and public payers, particularly Medicare, seemed more instrumental for women while private payers slightly more so for men. Such stands to reason given the facts that other than government health care insurance programs are predominantly purchased through employers in the US and over the life times of these generally now older people with colon cancer such opportunities have been much more available to men than to women.

\section{Potential limitations Internal validity}

Our use of ecological poverty measures might suggest alternative explanations for our results though we intended them to be contextual neighborhood measures, rather than compositional personal measures. Still, one might wonder if the racial/ethnic composition of high poverty neighborhoods, rather than their concentration of poor households, accounted for the colon cancer survival differences we observed. First, recent US studies of colon cancer diagnosis, treatment and survival have 
Table 6 Logistic regression results for main effects of neighborhood poverty and primary payer on chemotherapy receipt and post-surgical wait for chemotherapy of $\mathbf{6 0}$ days or more among patients with stage II or stage III colon cancer

\begin{tabular}{|c|c|c|c|c|c|c|}
\hline \multirow[b]{2}{*}{ Predictor variables } & \multicolumn{3}{|c|}{ Single predictor models } & \multicolumn{3}{|c|}{ Full models } \\
\hline & $\mathrm{No}^{\mathrm{a}}$ & OR & $(95 \% \mathrm{Cl})$ & $\mathrm{No}^{\mathrm{a}}$ & OR & $(95 \% \mathrm{Cl})$ \\
\hline \multicolumn{7}{|c|}{ Received chemotherapy after surgery } \\
\hline \multicolumn{7}{|l|}{ Neighborhood poverty } \\
\hline$<5 \%$ poor & 1,103 & 1.00 & & 1,103 & 1.00 & \\
\hline $5-29 \%$ poor & 1,066 & 0.80 & $(0.65,0.98)$ & 1,066 & 0.80 & $(0.65,0.98)$ \\
\hline$\geq 30 \%$ poor & 1,045 & 0.63 & $(0.52,0.78)$ & 1,045 & 0.65 & $(0.52,0.80)$ \\
\hline \multicolumn{7}{|l|}{ Primary payer } \\
\hline Uninsured & 164 & 1.00 & & 164 & 1.00 & \\
\hline Medicaid & 147 & 0.49 & $(0.30,0.81)$ & 147 & 0.51 & $(0.31,0.85)$ \\
\hline Medicare & 1,436 & 0.75 & $(0.51,1.11)$ & 1,436 & $0.71^{*}$ & $(0.48,1.04)$ \\
\hline Private & 1,467 & 0.85 & $(0.60,1.22)$ & 1,467 & 0.75 & $(0.52,1.09)$ \\
\hline \multicolumn{7}{|c|}{ Waited 60 days or more for adjuvant chemotherapy } \\
\hline \multicolumn{7}{|l|}{ Neighborhood poverty } \\
\hline$<5 \%$ poor & 421 & 1.00 & & 421 & 1.00 & \\
\hline $5-29 \%$ poor & 369 & 1.48 & $(1.01,2.18)$ & 369 & $1.45^{*}$ & $(0.98,2.14)$ \\
\hline$>30 \%$ poor & 326 & 1.55 & $(1.04,2.30)$ & 326 & 1.33 & $(0.88,2.02)$ \\
\hline \multicolumn{7}{|l|}{ Primary payer } \\
\hline Uninsured & 90 & 1.00 & & 90 & 1.00 & \\
\hline Medicaid & 58 & 0.87 & $(0.40,1.86)$ & 58 & 0.85 & $(0.39,1.83)$ \\
\hline Medicare & 364 & 0.42 & $(0.24,0.76)$ & 364 & 0.43 & $(0.24,0.77)$ \\
\hline Private & 604 & 0.41 & $(0.24,0.69)$ & 604 & 0.43 & $(0.25,0.73)$ \\
\hline
\end{tabular}

Notes. $\mathrm{OR}=$ odds ratio, $\mathrm{Cl}=$ confidence interval. All effects were age- and stage-adjusted across these categories: $25-59,60-69,70-79$ and 80 or older; and stage II or stage III.

$* \mathrm{p}<.10$.

consistently found that socioeconomic differences explained most racial-group differences [26,70-74]. Second, although we did not account for this factor in the present analysis as it was outside its scope, we are concomitantly performing related analyses that will soon be reported. We have found, for example, that health insurance also mediates ethnicity-breast cancer care relationships, accounting for many of the disadvantages observed among Hispanic women. In short, while not refuting previous inferences about the importance of race, ethnicity and culture in cancer care, our analyses suggest that having adequate health insurance is probably much more important.

For now, we do not think that race/ethnicity confounded this analysis for the following reasons. Twothirds of our sample was comprised of non-Hispanic white people. Even within our subsample of high poverty neighborhood residents, nearly half of them were nonHispanic white people. Most importantly, we were able to systematically replicate both our mediation and moderation hypothesis tests for non-Hispanic white women and women of color (Hispanic, non-Hispanic black, Asian-Pacific Islanders and American Indian people) as well as systematically replicate similar main effects of poverty and health insurance for non-Hispanic men and for men of color.

There has been a largely unmet need for research on the construct validity of ecological socioeconomic measures that are so often used in public health research. Wilson, Jargowsky and Bane added much relevant knowledge on high poverty neighborhood measures [10-12], and our research group has done some work to advance understandings of poor neighborhoods, analogous to this study's middle poverty neighborhoods [2,3]. They seem prevalently represented by not only the poor, but the near poor and working poor as well as lower-middle and middle class people. This study added further to our knowledge about vulnerable neighborhoods. For the first time that we are aware, steep monotonic gradients were observed for various types of health insurance across low poverty (e.g., baseline Medicaid coverage of women), middle poverty (prevalence 3-fold greater) and high poverty neighborhoods (prevalence more than 6-fold greater, Table $1[75,76])$. This new knowledge concerning the construct validity of ecological poverty measures may advance our understanding about the context in 
Table 7 logistic regression results for main effects and interactions of neighborhood poverty and primary payer by gender on receipt of optimum treatment ${ }^{a}$ among colon cancer patients with stage III disease

\begin{tabular}{|c|c|c|c|c|c|c|}
\hline \multirow[b]{2}{*}{ Predictor variables } & \multicolumn{3}{|c|}{ Women } & \multicolumn{3}{|c|}{ Men } \\
\hline & No. $^{b}$ & OR & $(95 \% \mathrm{Cl})$ & No. $^{b}$ & OR & $(95 \% \mathrm{Cl})$ \\
\hline \multicolumn{7}{|c|}{ Single predictor models } \\
\hline \multicolumn{7}{|l|}{ Neighborhood poverty } \\
\hline$<5 \%$ poor & 133 & 1.00 & & 133 & 1.00 & \\
\hline $5-29 \%$ poor & 131 & 0.53 & $(0.32,0.88)$ & 115 & 0.98 & $(0.58,1.66)$ \\
\hline$\geq 30 \%$ poor & 109 & 0.55 & $(0.32,0.95)$ & 103 & 0.88 & $(0.51,1.50)$ \\
\hline \multicolumn{7}{|l|}{ Primary payer } \\
\hline Uninsured & 29 & 1.00 & & 27 & 1.00 & \\
\hline Medicaid & 24 & 0.84 & $(0.26,2.72)$ & 15 & 0.67 & $(0.19,2.42)$ \\
\hline Medicare & 131 & 0.52 & $(0.21,1.30)$ & 119 & 1.47 & $(0.59,3.66)$ \\
\hline Private & 189 & 0.86 & $(0.37,2.00)$ & 190 & 1.06 & $(0.46,2.44)$ \\
\hline \multicolumn{7}{|c|}{ Full models } \\
\hline
\end{tabular}

Neighborhood poverty

\begin{tabular}{|c|c|c|c|c|c|c|}
\hline$<5 \%$ poor & 133 & 1.00 & & 133 & 1.00 & \\
\hline $5-29 \%$ poor & 131 & 0.53 & $(0.32,0.89)$ & 115 & 0.28 & $(0.10,0.77)$ \\
\hline$\geq 30 \%$ poor & 109 & 0.55 & $(0.31,0.98)$ & 103 & 0.08 & $(0.01,0.47)$ \\
\hline \multicolumn{7}{|l|}{ Primary payer } \\
\hline Uninsured & 29 & 1.00 & & 27 & 1.00 & \\
\hline Medicaid & 24 & 0.82 & $(0.25,2.68)$ & 15 & 0.41 & $(0.10,1.70)$ \\
\hline Medicare & 131 & 0.47 & $(0.19,1.21)$ & 119 & $0.22^{*}$ & $(0.04,1.20)$ \\
\hline Private & 189 & 0.72 & $(0.30,1.72)$ & 190 & $0.27^{*}$ & $(0.07,1.06)$ \\
\hline Poverty by payer & \multicolumn{3}{|c|}{ Null Interaction removed } & 351 & 1.75 & $(1.19,2.57)$ \\
\hline \multicolumn{7}{|c|}{ Poverty by payer interaction among men } \\
\hline & \multicolumn{3}{|c|}{$>30 \%$ poor } & \multicolumn{3}{|c|}{$<30 \%$ poor } \\
\hline & No. & OR & $(95 \% \mathrm{Cl})$ & No. ${ }^{b}$ & OR & $(95 \% \mathrm{Cl})$ \\
\hline \multicolumn{7}{|l|}{ Primary payer } \\
\hline Uninsured & 10 & 1.00 & & 17 & 1.00 & \\
\hline Medicaid & 9 & 3.03 & $(0.43,21.33)$ & 6 & 0.22 & $(0.03,1.69)$ \\
\hline Medicare & 37 & 13.33 & $(2.42,73.50)$ & 82 & 0.40 & $(0.10,1.60)$ \\
\hline Private & 47 & $3.69^{*}$ & $(0.81,16.84)$ & 143 & 0.41 & $(0.11,1.51)$ \\
\hline
\end{tabular}

Notes. $\mathrm{OR}=$ odds ratio, $\mathrm{Cl}=$ confidence interval. All effects were age-adjusted across these categories: $25-59,60-69,70-79$ and 80 or older.

a Optimum treatment: received colon cancer-directed surgery within 30 days of diagnosis and received adjuvant chemotherapy within 45 days of surgery.

${ }^{\mathrm{b}}$ Number of incident colon cancer cases.

${ }^{*} \mathrm{p}<.10$.

which very poor Americans live. Therefore, our findings are probably not prone to ecological fallacy. They may, in fact, help researchers to better understand their contextual measures and so avoid individualistic fallacies of inference [77,78]. Finally, the preferential predictive validity of our census tract-based poverty measure was consistent with that observed by others $[50,51]$. After such poverty measures entered this study's analytic models, no education or occupationbased measures did.

Another possible limitation of our study was incomplete information on outpatient treatments $[79,80]$. Such data are more difficult for cancer registries to collect than inpatient data. However, the California cancer registry has been shown to be nearly complete for chemotherapy data $(85 \%)$ in one place that we sampled, San Francisco [81]. In addition, analyses of hospitalbased surgery, lymph node evaluation, stage and survival were unlikely to have been affected [82], and missing chemotherapy data were not prevalent in our sample.

We focused on all-cause or overall survival, rather than cancer-specific survival. Cancer was the underlying cause of death among the vast majority of patients in our sample (72\%) who died during the study period, accounting for nearly 8 of every 10 deaths (78\%), for example, among perhaps the most policy-interesting group for its observed socioeconomic gradients, those with stage III colon cancer. Although vital status and length 
of overall survival are highly accurate in cancer registries, the underlying cause of death probably is not [8385]. Although death certificate error was a likely limitation, we did systematically replicate our central all-cause survival hypothesis tests with cancer-specific ones. If anything, our overall survival effects were probably slight underestimates of cancer-specific ones [84]. Finally, the underlying cause of many deaths not coded as cancer mortality can be directly associated with lack of treatment or with cancer treatment complications [86]. For all of these reasons, we think overall survival a more policy-telling indicator of practical clinical and human significance.

\section{External validity}

This study's sample of people with colon cancer may not be generalizable to all such people across the US. Purposively diverse and potentially policy-important places in California were oversampled: high poverty neighborhoods in very large urban to rural places. Admittedly, our findings are most generalizable to such places. Previous research has suggested that such high poverty places probably have some important commonalities across America [10-12]. It should also be noted that after accounting for demographic, socioeconomic and clinical factors, place (large urban, smaller urban or rural) did not seem to matter in this study's analytic models. This study's inferences, therefore, can probably be confidently generalized across many states, especially to their high poverty neighborhoods. Finally, one may wonder about the apparent non-significance of geographic place in these analyses. Are there not critical elements of geography that are already well known to be associated with health care access and effectiveness: urbanity, health care service endowments, distances to such services and the like? Surely there are and so, yes, geographic place matters. Our analysis points out though that the socioeconomic elements of place, particularly the main, mediating and moderating effects of highly concentrated impoverishment, probably matters much more.

We think that some of our analyses were statistically powerful, especially, tests of poverty-health insurancecolon cancer survival mediation hypotheses that typically analyzed survival among approximately 3,000 women and 3,000 men with approximately 1,000 study participants in each of three poverty groups. Even their uninsured subsamples in the range of 250 to 300 probably ensured detection of important effects. These analyses tended to provide rather precise effect estimates, engendering substantial scientific and policy confidence. Admittedly, a few of the moderator hypotheses we examined, especially those related to the increasingly specific experiences, for example, of uninsured or underinsured women or men in high poverty neighborhoods who were treated optimally for stage III colon cancer, where key subsamples ranged as low as 10 to 25, were necessarily exploratory. We hope that other researchers, especially those with access to national cancer data, will systematically replicate and extend our analyses.

\section{Conclusions}

Health insurance substantially mediates the quality of colon cancer care in the United States. Moreover, poverty seems to make the effects of being uninsured or underinsured even worse, especially among women. These findings are consistent with the theory that more facilitative social and economic capital is available in more affluent neighborhoods, where people with cancer may be better able to absorb the indirect and uncovered direct costs of care. Policy makers need to understand that even covered health care presently comes with myriad such costs. And though some are able to absorb them, many others are not.

\section{Additional file}

Addtional file 1: Additional tabular presentations related to

practical significance. Rates and rate ratios.

\section{Competing interests}

The authors declare that they have no competing interests.

\section{Authors' contributions}

KMG conceptualized and supervised the study and led the writing. KMG, INL, EJH, GYZ and CH obtained funding. GYZ supervised the analysis. All authors assisted with study design, data analysis and interpretation, and writing. All authors read and approved the final manuscript.

\section{Acknowledgements}

This research was supported in part with funds from the Canadian Institutes of Health Research (grant no. 67161). The authors gratefully acknowledge the administrative and logistical assistance of Kurt Snipes, Janet Bates and Gretchen Agha of the Chronic Disease Surveillance and Research Branch, California Department of Public Health. We also gratefully acknowledge the research and technical assistance of Nancy Richter of the University of Windsor and Mark Allen and Allyn Fernandez-Ami of the California Cancer Registry.

The collection of cancer incidence data used in this study was supported by the California Department of Public Health as part of the statewide cancer reporting program mandated by California Health and Safety Code Section 103885; the National Cancer Institute's Surveillance, Epidemiology and End Results Program under contract HHSN261201000140C awarded to the Cancer Prevention Institute of California, contract HHSN261201000035C awarded to the University of Southern California, and contract HHSN261201000034C awarded to the Public Health Institute; and the Centers for Disease Control and Prevention's National Program of Cancer Registries, under agreement U58DP003862-01 awarded to the California Department of Public Health. The ideas and opinions expressed herein are those of the authors and endorsement by the State of California,

Department of Public Health the National Cancer Institute, and the Centers for Disease Control and Prevention or their contractors and subcontractors is not intended nor should be inferred. 


\section{Author details}

'School of Social Work, University of Windsor, 401 Sunset Avenue, Windsor, Ontario N9B 3P4, Canada. ${ }^{2}$ Department of Geography, University of Western Ontario, London, Ontario, Canada. ${ }^{3}$ Dalla Lana School of Public Health, University of Toronto, Toronto, Ontario, Canada. ${ }^{4}$ Department of Epidemiology and Biostatistics, and Robarts Research Institute, University of Western Ontario, London, Ontario, Canada. ${ }^{5}$ Windsor Regional Cancer Center and School of Medicine and Dentistry, Department of Medicine, Division of General Internal Medicine, University of Western Ontario, London, Ontario, Canada. ${ }^{6}$ Faculty of Health Sciences, University of Ontario Institute of Technology, Oshawa, Ontario, Canada. 'Windsor Regional Cancer Center, Windsor, Ontario, Canada. ${ }^{8}$ School of Social Work, University of Windsor, Windsor, Ontario, Canada. ${ }^{9}$ School of Social Work, University of Windsor, Windsor, Ontario, Canada. ${ }^{10}$ Division of General Surgery, Sunnybrook Health Sciences Center and cross appointed to the Departments of Surgery, and Health Policy, Management and Evaluation, University of Toronto, Toronto, Ontario, Canada.

Received: 14 June 2012 Accepted: 16 October 2012

Published: 24 October 2012

\section{References}

1. Gorey KM, Holowaty EJ, Fehringer G, Laukkanen E, Webster DJ, Moskowitz A, Richter NL: An international comparison of cancer survival: Toronto, Ontario, and Detroit, Michigan, metropolitan areas. Am J Public Health 1997, 87:1156-1163.

2. Gorey KM, Holowaty EJ, Fehringer G, Laukkanen E, Richter NL, Meyer CM: An international comparison of cancer survival: Toronto, Ontario and Honolulu, Hawaii. Am J Public Health 2000, 90:1866-1872.

3. Gorey KM, Kliewer E, Holowaty EJ, Laukkanen E, Ng EY: An international comparison of breast cancer survival: Winnipeg, Manitoba and Des Moines, lowa metropolitan areas. Ann Epidemiol 2003, 13:32-41.

4. Gorey KM, Luginaah IN, Holowaty EJ, Fung KY, Hamm C: Breast cancer survival in Ontario and California, 1998 to 2006: socioeconomic inequity remains much greater in the United States. Ann Epidemiol 2009, 19:121-124.

5. Gorey KM, Luginaah IN, Holowaty EJ, Fung KY, Hamm C: Wait times for surgical and adjuvant radiation treatment of breast cancer in Canada and the United States: greater socioeconomic inequity in America. Clin Invest Med 2009, 32:E239-E249.

6. Gorey KM, Luginaah IN, Bartfay E, Fung KY, Holowaty EJ, Wright FC, Hamm C, Kanjeekal SM, Balagurusamy MK: Associations of physician supplies with colon cancer care in Ontario and California, 1996 to 2006. Dig Dis Sci 2011, 56:523-531.

7. Boyd C, Zhang-Salomons JY, Groome PA, Mackillop WJ: Association between community income and cancer survival in Ontario, Canada, and the United States. J Clin Oncol 1999, 17:2244-2255.

8. Zhang-Salomons J, Qian H, Holowaty E, Mackillop WJ: Associations between socioeconomic status and cancer survival: choice of SES indicator may affect results. Ann Epidemiol 2006, 16:521-528.

9. Gorey KM, Luginaah IN, Bartfay E, Fung KY, Holowaty EJ, Wright FC, Hamm C, Kanjeekal SM: Effects of socioeconomic status on colon cancer treatment accessibility and survival in Toronto, Ontario, and San Francisco, California, 1996-2006. Am J Public Health 2011, 101:112-119.

10. Wilson WJ: The truly disadvantaged: the inner city, the underclass, and public policy: University of Chicago Press; 1987.

11. Jargowsky PA: Poverty and place: ghettos, barrios, and the American city New York: Russell Sage Foundation; 1997.

12. Jargowsky PA, Bane MJ: Ghetto poverty in the United States, 1970-1980 In The urban underclass (pp. 235-273). Edited by Jencks C, Peterson PE. Washington DC: The Brookings Institution; 1991.

13. Gorey KM: Breast cancer survival in Canada and the United States: metaanalytic evidence of a Canadian advantage in low-income areas. Int J Epidemiol 2009, 38:1543-1551.

14. Gorey KM, Luginaah IN, Hamm C, Fung KY, Holowaty EJ: Breast cancer care in Canada and the United States: ecological comparisons of extremely impoverished and affluent urban neighborhoods. Health Place 2010, 16:156-163.
15. Edwards BK, Ward E, Kohler BA, Eheman C, Zauber AG, Anderson RN Jemal A, Schymura MJ, Lansdorp-Vogelaar I, Seeff LC, van Ballegooijen M, Goede SL, Ries LAG: Annual report to the nation on the status of cancer, 1975-2006, featuring colorectal cancer trends and impact of interventions (risk factors, screening, and treatment) to reduce future rates. Cancer 2010, 116:544-573.

16. Lee W, Nelson R, Mailey B, Duldulao MP, Garcia-Aguilar J, Kim J: Socioeconomic factors impact colon cancer outcomes in diverse patient populations. J Gastrointest Surg 2012, 16:692-704.

17. Lincourt AE, Sing RF, Kercher KW, Stewart A, Demeter BL, Hope WW, Lang NP, Greene FL, Heniford BT: Association of demographic and treatment variables in long-term colon cancer survival. Surg Innov 2008, 15:17-25.

18. Polednak A: Poverty, comorbidity, and survival of colorectal cancer patients diagnosed in Connecticut. J Health Care Poor Underserved 2001, 12:302-310

19. Gorey KM, Holowaty EJ, Fehringer G, Laukkanen E, Richter NL, Meyer CM: An international comparison of cancer survival: relatively poor areas of Toronto, Ontario, and three US metropolitan areas. J Public Health Med 2000, 22:343-348.

20. Chao A, Connell CJ, Cokkinides V, Jacobs EJ, Calle EE, Thun MJ: Underuse of screening sigmoidoscopy and colonoscopy in a large cohort of US adults. Am J Public Health 2004, 94:1775-1781.

21. Figueredo A, Coombes ME, Mukherjee S: Adjuvant therapy for completely resected stage II colon cancer. Cochrane Database Syst Rev 2008, (3). CD005390

22. Etzioni DA, El-Khoueiry AB, Beart RW: Rates and predictors of chemotherapy use for stage III colon cancer: a systematic review. Cancer 2008, 113:3279-3289.

23. Palmer RC, Schneider EC: Social disparities across the continuum of colorectal cancer: a systematic review. Cancer Causes Control 2005, 16:55-61.

24. Hsieh MC, Velasco C, Wu X-C, Pareti LA, Andrews PA, Chen VW: Influence of socioeconomic status and hospital type on disparities of lymph node evaluation in colon cancer patients. Cancer 2012, 118:1675-1683.

25. McBride RB, Lebwohl B, Hershman DL, Neugut Al: Impact of socioeconomic status on extent of lymph node dissection for colon cancer. Cancer Epidemiol Biomarkers Prev 2010, 19:738-745.

26. Morgan JW, Cho MM, Guenzi CD, Jackson C, Mathur A, Natto Z, Kazanjian K, Tran H, Shavlik D, Lum SS: Predictors of delayed-stage colorectal cancer: are we neglecting critical demographic information? Ann Epidemiol 2011, 21:914-921.

27. Halpern MT, Pavluck AL, Ko CY, Ward EM: Factors associated with colon cancer stage at diagnosis. Dig Dis Sci 2009, 54:2680-2693.

28. VanEenwyk J, Campo JS, Ossiander EM: Socioeconomic and demographic disparities in treatment of carcinoma of the colon and rectum. Cancer 2002, 95:39-46.

29. Elston Lafata J, Cole Johnson C, Ben-Menachem T, Morlock R : Sociodemographic differences in the receipt of colorectal cancer surveillance care following treatment with curative intent. Med Care 2001, 39:361-372.

30. Halpern MT, Ward EM, Pavluck AL, Schrag NM, Bian J, Chen AY: Association of insurance status and ethnicity with cancer stage at diagnosis for 12 cancer sites: a retrospective analysis. Lancet Oncol 2008, 9:222-231.

31. Chagpar R, Xing Y, Chiang Y-J, Feig BW, Chang GJ, You YN, Cormier JN: Adherence to stage-specific treatment guidelines for patients with colon cancer. J Clin Oncol 2012, 30:972-979.

32. Foley KL, Tooze JA, Klepin HD, Song EY, Geiger AM: Adjuvant chemotherapy among Medicaid-enrolled patients diagnosed with nonmetastatic colon cancer. Am J Clin Oncol 2011, 34:120-124.

33. Kirkpatrick HM, Aitelli $\mathrm{CL}$, Qin $\mathrm{H}$, Becerra C, Lichliter WE, McCollum AD: Referral patterns and adjuvant chemotherapy use in patients with stage II colon cancer. Clin Colorectal Cancer 2010, 9:150-156.

34. Bradley CJ, Given CW, Dahman B, Fitzgerald TL: Adjuvant chemotherapy after resection in elderly Medicare and Medicaid patients with colon cancer. Arch Intern Med 2008, 168:521-529.

35. Koroukian SM, Bakaki PM, Raghavan D: Survival disparities by Medicaid status: an analysis of 8 cancers. Cancer 2012, 118:4271-4279. 
36. Roetzheim RG, Pal N, Gonzalez EC, Ferrante JM, Van Durme DJ, Krischer JP: Effects of health insurance and race on colorectal cancer treatments and outcomes. Am J Public Health 2000, 90:1746-1754

37. Gorey KM, Luginaah IN, Schwartz KL, Fung KY, Balagurusamy M, Bartfay E, Wright FC, Anucha U, Parsons RR: Increased racial differences on breast cancer care and survival in America: Historical evidence consistent with a health insurance hypothesis, 1975 to 2001. Breast Cancer Res Treat 2009, 113:595-600.

38. Shankaran V, Jolly S, Blough D, Ramsey SD: Risk factors for financial hardship in patients receiving adjuvant chemotherapy for colon cancer: a population-based exploratory analysis. J Clin Oncol 2012 30:1608-1614.

39. Bradley CJ: Financial hardship: a consequence of survivorship? J Clin Oncol 2012, 30:1579-1580.

40. DeNavas-Walt C, Proctor BD, Smith JC: Income, poverty, and health insurance coverage in the United States: 2010. Current population reports: consumer income (P60-239). Washington, DC: US Census Bureau; 2011.

41. Collins S, Rustgis S, Doty M: Realizing health reform's potential: women and the Affordable Care Act of 2010. Washington, DC: The Commonwealth Fund; 2010.

42. North American Association of Central Cancer Registries: Data quality assessments; 2008. Available at: http://www.naaccr.org. Accessed May 12, 2012.

43. National Cancer Institute: Surveillance, epidemiology, and end results (SEER); 2008. Available at: http://www.seer.cancer.gov. Accessed May 12, 2012

44. International Classification of Diseases: Ninth Revision. Geneva: World Health Organization; 1980

45. 2000 Census of population and housing in California: summary tape file 3 on CD-ROM. Washington DC: US Census Bureau; 2002

46. Shugarman LR, Sorbero MES, Tian H, Jain AK, Ashwood JS: An exploration of urban and rural differences in lung cancer survival among Medicare beneficiaries. Am J Public Health 2008, 98:1280-1287.

47. Statistics Canada: Definitions of "rural". Ottawa: Statistics Canada; 2002.

48. Fleiss $\mathrm{J}$ : Statistical methods for rates and proportions. 2nd edition. New York: John Wiley \& Sons; 1981

49. Faul F, Erdfelder E, Lang AG, Buchner A: G*Power 3: a flexible statistical power analysis program for the social, behavioral, and biomedical sciences. Behav Res Meth 2007, 39:175-191.

50. Krieger N, Chen JT, Waterman PD, Rehkopf DH, Subramanian SV: Race/ ethnicity, gender, and monitoring socioeconomic gradients in health: a comparison of area based socioeconomic measures-the Public Health Disparities Geocoding Project. Am J Public Health 2003, 93:1655-1671.

51. Krieger N, Chen JT, Waterman PD, Soobader M, Subramanian SV, Carson R: Geocoding and monitoring of US socioeconomic inequalities in mortality and cancer incidence: does the choice of area-based measure and geographic level matter? The Public Health Disparities Geocoding Project. Am J Epidemiol 2002, 156:471-482.

52. Lee BA, Marlay M: The right side of the tracks: affluent neighborhoods in the metropolitan United States. Soc Sci Q 2007, 88:766-789.

53. California Cancer Registry: Cancer reporting in California: abstracting and coding procedures for hospitals. California cancer reporting system standards, Vol 1. 7th edition. Sacramento: Department of Health Services, Cancer Surveillance Section; 2003.

54. Greene FL, Page DL, Fleming ID, Fritz A, Balch CM, Haller DG, Morrow M (Eds): AJCC staging manual. 6th edition. NY: SpringerVerlag; 2002

55. Fritz $A$, Ries $L$ (Eds): SEER extent of disease: codes and coding instructions. 3rd edition. Bethesda: National Cancer Institute; 1998

56. Wright FC, Law CHL, Berry S, Smith AJ: Clinically important aspects of lymph node assessment in colon cancer. J Surg Oncol 2009, 99:248-255.

57. Bilimoria KY, Bentrem DJ, Stewart AK, Talamonti MS, Winchester DP, Russell TR, Ko CY: Lymph node evaluation as a colon cancer quality measure: a national hospital report card. J Natl Cancer Inst 2008, 100:1310-1317.

58. Chang GJ, Rodriguez-Bigas MA, Skibber JM, Moyer VA: Lymph node evaluation and survival after curative resection of colon cancer: systematic review. J Natl Cancer Inst 2007, 99:433-441.

59. Simunovic M, Rempel E, Thériault M-E, Baxter NN, Virnig BA, Meropol NJ, Levine MN: Influence of delays to nonemergent colon cancer surgery on operative mortality, disease-specific survival and overall survival. Can J Surg 2009, 52:E79-E86.

60. Bayraktar UD, Chen E, Bayraktar S, Sands LR, Marchetti F, Montero AJ Rocha-Lima CMS: Does delay of adjuvant chemotherapy impact survival in patients with resected stage II and III colon adenocarcinoma? Cancer 2011, 117:2364-2370

61. Czaykowski P, Gill S, Kennecke H, Turner D, Gordon V: Adjuvant chemotherapy (AC) for stage 3 colon cancer: does timing matter? Orlando: Paper presented at the Gastrointestinal Cancers Symposium; 2007.

62. Chau I, Norman AR, Cunningham D, Tait D, Ross PJ, Iveson T, Hill M, Hickish $T$, Lofts F, Jodrell D, Webb A, Oates JR: A randomized comparison between 6 months of bolus fluorouracil/leucovorin and 12 weeks of protracted venous infusion fluorouracil as adjuvant treatment in colorectal cancer. Ann Oncol 2005, 16:549-557.

63. Greenland S: Introduction to regression modeling. In Modern Epidemiology. 2nd edition. Edited by Rothman KJ, Greenland S. Philadelphia: LippincottRaven Publishers; 1998:401-432.

64. Gorey KM: Regarding "Associations between socioeconomic status and cancer survival.". Ann Epidemiol 2006, 16:789-791.

65. Hosmer DW, Lemeshow S: Applied logistic regression. 2nd edition. NY: John Wiley \& Sons; 2000

66. Agresti A: Categorical data analysis. Hoboken: John Wiley \& Sons; 2002

67. Greenland S: Interpretation and choice of effect measures in epidemiologic analysis. Am J Epidemiol 1987, 125:761-768.

68. Mantel N, Haenszel W: Statistical aspects of the analysis of data from retrospective studies of disease. J Natl Cancer Inst 1959, 22:719-748.

69. Miettinen OS: Estimability and estimation in case referent-studies. Am J Epidemiol 1976, 103:226-235.

70. Yan B, Noone AM, Yee C, Banerjee M, Schwartz K, Simon MS: Racial differences in colorectal cancer survival in the Detroit metropolitan area. Cancer 2009, 115:3791-3800.

71. Gross $C P$, Smith BD, Wolf $E$, Andersen M: Racial disparities in cancer therapy: did the gap narrow between 1992 and 2002? Cancer 2008, 112:900-908.

72. Le H, Ziogas A, Lipkin SM, Zell JA: Effects of socioeconomic status and treatment disparities in colorectal cancer survival. Cancer Epidemiol Biomarkers Prev 2008, 17:1950-1962.

73. Du XL, Meyer TE, Franzini L: Meta-analysis of racial disparities in survival in association with socioeconomic status among men and women with colon cancer. Cancer 2007, 109:2161-2170.

74. Gomez SL, O'Malley CD, Stroup A, Shema SJ, Satariano WA: Longitudinal, population-based study of racial/ethnic differences in colorectal cancer survival: impact of neighborhood socioeconomic status, treatment and comorbidity. BMC Cancer 2007, 7:193.

75. Verrill C: Assessing the reliability and validity of primary payer information in central cancer registry data. Quebec: Paper presented at the annual meeting of the North American Association of Central Cancer Registries; 2010.

76. Chan JK, Gomez SL, O'Malley CD, Perkins Cl, Clarke CA: Validity of cancer registry Medicaid status against enrollment files: implications for population-based studies of cancer outcomes. Med Care 2008, 44:952-955.

77. Subramanian SV, Jones K, Kaddour A, Krieger N: Revisiting Robinson: the perils of individualistic and ecologic fallacy. Int J Epidemiol 2009, 38:342-360.

78. Silver E: Race, neighborhood disadvantage, and violence among persons with mental disorders: the importance of contextual measurement. Law Hum Behav 2000, 24:449-456.

79. Lund MJ, Brawley OP, Ward KC, Young JL, Gabram SS, Eley JW: Parity and disparity in first course treatment of invasive breast cancer. Breast Cancer Res Treat 2008, 109:545-557.

80. Malin JL, Kahn KL, Adams J, Kwan L, Laouri M, Ganz PA: Validity of cancer registry data for measuring the quality of breast cancer care. $J$ Natl Cancer Inst 2002, 94:835-844.

81. Cress RD, Zaslavsky AM, West DW, Wolf RE, Felter MC, Ayanian JZ: Completeness of information on adjuvant therapies for colorectal cancer in population-based cancer registries. Med Care 2003, 41:1006-1012.

82. Cooper GS, Virnig B, Klabunde CN, Schussler N, Freeman J, Warren JL: Use of SEER-Medicare data for measuring cancer surgery. Med Care 2002 40(8 Suppl):IV43-48. 
83. Yin D, Morris $C R$, Bates $J H$, German RR: Effect of misclassified underlying cause of death on survival estimates of colon and rectal cancer. J Natl Cancer Inst 2011, 20(103):1130-1133

84. Hsiao FY, Mullins CD, Onukwugha E, Pandya N, Hanna N: Comparative effectiveness of different chemotherapeutic regimens on survival of people aged 66 and older with stage III colon cancer: a "real world" analysis using Surveillance, Epidemiology, and End Results-Medicare data. J Am Geriatr Soc 2011, 59:1717-1723.

85. Lenfant C, Freidman L, Thom T: Fifty years of death certificates: the Framingham Heart Study. Ann Intern Med 1998, 129:1066-1067.

86. Brown BW, Brauner C, Minnotte MC: Noncancer deaths in White adult cancer patients. J Natl Cancer Inst 1993, 85:979-987.

\section{doi:10.1186/1471-2458-12-897}

Cite this article as: Gorey et al:: Effects of being uninsured or underinsured and living in extremely poor neighborhoods on colon cancer care and survival in California: historical cohort analysis, 19962011. BMC Public Health 2012 12:897.

\section{Submit your next manuscript to BioMed Central and take full advantage of:}

- Convenient online submission

- Thorough peer review

- No space constraints or color figure charges

- Immediate publication on acceptance

- Inclusion in PubMed, CAS, Scopus and Google Scholar

- Research which is freely available for redistribution 